\title{
Exploring effective micro-level items for evaluating inclusive walking facilities on urban streets (applied in Johor Bahru, Malaysia)
}

\author{
Zohreh Asadi-Shekari ${ }^{\mathrm{a}}$, Mehdi Moeinaddini ${ }^{\mathrm{b}, *}$, Mahdi Aghaabbasi ${ }^{\mathrm{b}}$, Mario Cools ${ }^{\mathrm{c}, \mathrm{d}, \mathrm{e}}$, \\ Muhammad Zaly Shah ${ }^{\mathrm{b}}$ \\ ${ }^{a}$ Centre for Innovative Planning and Development (CIPD), Faculty of Built Environment and Surveying, Universiti Teknologi Malaysia, 81310 Skudai, Johor, Malaysia \\ ${ }^{\mathrm{b}}$ Department of Urban and Regional Planning, Faculty of Built Environment and Surveying, Universiti Teknologi Malaysia, 81310 Skudai, Johor, Malaysia \\ ${ }^{\mathrm{c}}$ Local Environment \& Management Analysis (LEMA), Urban and Environmental Engineering (UEE), University of Liège, Allée de la Découverte, Quartier Polytech, 4000 \\ Liège, Belgium \\ ${ }^{\mathrm{d}}$ KULeuven Campus Brussels, Department of Informatics, Simulation and Modeling, Warmoesberg 26, 1000 Brussels, Belgium \\ ${ }^{\mathrm{e}}$ Hasselt University, Faculty of Business Economics, Agoralaan Gebouw D, 3590 Diepenbeek, Belgium
}

\section{A R T I C L E I N F O}

\section{Keywords:}

Pedestrian level of service

Inclusive streets

Pedestrian-friendly streets

Points system

Evaluation model

\begin{abstract}
A B S T R A C T
Modern cities try to provide enough facilities for inclusive and pedestrian-friendly streets. Evaluating and designing models that consider a wide range of street users, including disabled people, can help urban planners to design these inclusive streets. The results of existing (but limited) studies evaluating street conditions for pedestrians do not include a wide range of street users. Therefore, this paper seeks to propose a new model for evaluating and improving urban streets, focusing on inclusive pedestrian facilities. This study introduces pedestrian mobility indicators using advanced design guidelines, existing literature and expert interviews. These indicators are evaluated by exploratory factor analysis (EFA) to find underlying patterns. Levels of association between observed and latent variables are tested by confirmatory factor analysis (CFA) and second-order confirmatory factor analysis (SOCFA). Structural equation modelling (SEM) is used to perform the CFA and SOCFA analyses. A questionnaire was used to collect data from 599 participants randomly selected from Setia Tropika residents (Johor, Malaysia). The resultant factor loading values are used as weights in an analytical points-based system, comparing existing facilities to a standard to estimate street facilities and infrastructure levels of service for pedestrians. This pedestrian level of service (PLOS) can be applied to various urban streets around the world, but in this study a street in Malaysia is evaluated using this method to check the accuracy of the proposed PLOS model. Existing street problems and potential improvements can be identified by this model.
\end{abstract}

\section{Introduction}

Although there are numerous studies regarding different aspects of sustainability (e.g., energy consumption, biodiversity, water and air pollution, fair distribution of income, etc.), sustainable living has received less attention (Cubukcu, 2013). Walking as part of a sustainable lifestyle can be categorized as sustainable living, which aims to reduce the effects of negative externalities to modern lifestyles, such as obesity and overweight (Larsen, 2014; McDonald, 2007). Various health and urban planning studies (e.g. Bader et al., 2015; De Vries, Bakker, Van Mechelen, \& Hopman-Rock, 2007; Rodriguez, Aytur, Forsyth, Oakes, \& Clifton, 2008) show that the availability of walking facilities is positively related to walking and physical activity rates.

In addition, there is growing concern over negative externalities associated with private motorized trips, such as air pollution, fuel consumption and safety problems (Moeinaddini, Asadi-Shekari, \& Zaly Shah, 2014; Moeinaddini, Asadi-Shekari, \& Zaly Shah, 2014; Moeinaddini, Asadi-Shekari, \& Zaly Shah, 2015; Moeinaddini, AsadiShekari, \& Zaly Shah, 2015). If automobile users shift to walking for short trips, the considerable amount of emissions and fuel consumption per mile associated with short trips can be reduced (Holbrow, 2013). A two to four per cent reduction in fuel consumption can be achieved if only one per cent of automobile users shift to walking (Litman, 2012). Walking is the primary mode of transportation for people around the world. This mode is flexible and has health benefits (Asadi-Shekari, Moeinaddini, \& Zaly Shah, 2014; Otak, 1997; Southworth, 2005; Tan, Wang, Lu, \& Bian, 2007). Walking is also the most affordable means of transportation since it is cheap and needs only some basic

\footnotetext{
* Corresponding author.

E-mail address: mehdi@utm.my (M. Moeinaddini).
} 
infrastructures (Aghaabbasi, Moeinaddini, Shah, \& Asadi-Shekari, 2017 and Aghaabbasi, Moeinaddini, Shah, \& Asadi-Shekari, 2018; AsadiShekari, Moeinaddini, \& Zaly Shah, 2015; Asadi-Shekari, Moeinaddini, \& Zaly Shah, 2015).

Despite the vast benefits of walking, most planning efforts tend to pay noticeably greater attention to motorized transportation. Findings from recent studies show that improvement of operational characteristics and the pedestrian environment can encourage people to walk, and directly influence people's quality of life, safety (Ewing, Handy, Brownson, Clemente, \& Winston, 2006; Mehta, 2008; Saelens, Sallis, \& Frank, 2003) and road congestion (Elias \& Shiftan, 2012). Sidewalk facility enhancements that consider a wide range of users lead to higher levels of satisfaction among people with diverse abilities (Asadi-Shekari et al., 2014).

By revealing the health and social benefits of walking in recent years, the need to create satisfactory walking environments has been stressed. People's satisfaction with their walking environment motivates them to choose walking as a habitual behaviour (Ettema et al., 2011). Creating a pleasant pedestrian environment can be achieved through sustained assessment and inspection of sidewalk facilities. However, assessing the pedestrian environment is more complicated than vehicle roadways (Landis, Vattikuti, Ottenberg, McLeod, \& Guttenplan, 2001).

'Level of service' (LOS) is an instrument for assessing the overall quality of service, street furnishing and infrastructure (Asadi-Shekari et al., 2014; Moeinaddini, Asadi-Shekari, Ismail, \& Zaly Shah, 2013). The pedestrian level of service (PLOS) is necessary for improving existing infrastructure and guiding new investments (Christopoulou \& Pitsiava-Latinopoulou, 2012). It helps designers and planners to identify shortcomings in pedestrian street environments and can suggest improvements for solving the problems. In other words, PLOS assesses the quality of street conditions for pedestrians.

In addition to pedestrian flow and volume (Fruin, 1971; HCM, 2000; Tanaboriboon \& Guyano, 1989), current PLOS methods assess different walking facilities, such as curb ramps, tactile pavements, accessible drinking fountains (Aghaabbasi et al., 2017; Asadi-Shekari et al., 2015a, 2015b; Asadi-Shekari et al., 2014), lighting, bollards, seating areas, the landscape, trees, driveways (Aghaabbasi et al., 2017; Clifton, Livi Smith, \& Rodriguez, 2007; Kihl, Brennan, Gabhawala, List, \& Mittal, 2005), toilets and rubbish bins (Aghaabbasi et al., 2017; Cunningham, Michael, Farquhar, \& Lapidus, 2005; Rahimiashtiani \& Ujang, 2013) in addition to maintenance, slopes and natural barriers (Clifton et al., 2007; Williams et al., 2005).

Some studies have defined the PLOS as a classification problem. For example, Sahani and Kumar (2017) used three methods of clustering, including affinity propagation, self-organizing maps in artificial neural networks and genetic algorithm-fuzzy (GA-Fuzzy) methods, to find the most suitable clustering. They found that the GA-Fuzzy is the most suitable one. However, this study just focused on capacity based on related factors, such as pedestrian space, flow, volume to capacity ratio and pedestrian speed. In addition, these studies focus on behavioural analysis rather than the main aim of PLOS, which is helping to identify shortcomings and suggesting improvements.

PLOS methods can be classified into two main types (Asadi-Shekari, Moeinaddini, \& Zaly Shah, 2013; Asadi-Shekari, Moeinaddini, \& Zaly Shah, 2013). The first type includes capacity-based models that focus on sidewalk capacity, pedestrian flow and volume (e.g., Fruin, 1971; HCM, 2000; Tanaboriboon \& Guyano, 1989). The second type includes roadway characteristics-based models that focus on design factors and pedestrian facilities (e.g., Asadi-Shekari et al., 2013a, 2013b; AsadiShekari et al., 2014; Khisty, 1994; Landis et al., 2001; Lautso \& Murole, 1974; Sarkar, 1993; Tan et al., 2007). The first approach has been criticized in various studies since these studies treat pedestrians like cars and do not consider pedestrians as special users with particular needs (Asadi-Shekari et al., 2013a, 2013b). In addition, a considerable number of studies have focused on evaluating the capacity of sidewalks.
Therefore, this study pays more attention to the second approach than the first one. Moreover, characteristics-based models consider micro design factors, such as sidewalk facilities, which have an important impact on pedestrian perceptions of their walking environment. This approach focuses on how safe/secure, attractive and comfortable a sidewalk segment or intersection is for pedestrians.

The first attempt to develop a PLOS model was organized by Fruin (1971). This model is based on pedestrian volume and sidewalk capacity. Tanaboriboon and Guyano (1989) followed Fruin's idea to assess the PLOS of walkways in Bangkok. Their PLOS model is based on area occupancy per person. These primary types of PLOS models exclude micro-level design factors from the assessment. Furthermore, sidewalk capacity-based PLOS models like HCM (2000) do not consider other important factors, such as street furniture. In addition, these models treat pedestrians like vehicles (Asadi-Shekari et al., 2013a, 2013b).

Pedestrian perceptions and expectations are other important factors in some of the PLOS studies. Kang and Xiong (2013) found pedestrian flow rates to be the most effective factor for PLOS perception, although other factors, such as sidewalk width, separation from traffic and onstreet parking, also have significant effects on PLOS perception in this study. Kadali and Vedagiri (2015) also concluded that perceived PLOS at un-signalized mid-block crosswalks can be affected by perceived safety, crossing difficulty, median width and land-use conditions, in addition to vehicular traffic-related factors, such as the number of vehicles encountered and number of lanes. However, many other factors (such as comfort, accessibility and sidewalk facilities) can affect PLOS perception.

The need to develop PLOS models that consider micro-level design factors has led to the introduction of characteristics-based PLOS models, which consider pedestrian facilities and infrastructure providing comfortable, secure, safe and convenient walking trips. Dixon's points-based rating system (1996) emphasizes the safety of pedestrians by considering factors like basic pedestrian facilities, amenities, conflicts and multiple travel options. The weights in this model are chosen arbitrarily. Miller, Bigelow, and Garber (2000) proposed the same idea (a points system) to assess the PLOS by using a simulation method (3dimentional visualization technique) to collect data. However, the limited range of facilities and street users make the results of these types of studies insufficient for a suitable evaluation model for inclusive streets.

Landis et al. (2001) proposed a PLOS model by considering pedestrian perceptions of the safety of roadside walking environments. In this method, factors significantly affecting pedestrian perceptions have been identified using an ordinary squares regression. Identified factors include lateral separation of pedestrians from motorized vehicles, the total number of lanes, motorized vehicle volume, motorized vehicle speed and sidewalk width. Although this PLOS method is commonly used as a reference for various studies, this model considers a limited number of factors, which may not convey the complexity of streets on one side of the equation, and provision for safety and convenience on the other, mainly because of regression model limitations.

Jensen (2007) developed a PLOS model by using video clips to identify the factors that affect pedestrian satisfaction regarding roadway segments. A logit model is used to estimate the PLOS. Factors like the type of walking area, average speed of motor vehicles and presence of medians have been used in this model. In comparison with Landis et al. (2001), Jensen (2007) used more indicators to assess the PLOS. However, these indicators do not include a wide range of users (e.g., disabled people). Asadi-Shekari et al. (2013a) proposed a PLOS model that considers micro-level design factors for a wide range of users, including disabled people. The weights of the indicators in this study are estimated based on the importance of factors in different guidelines. Therefore, pedestrian perceptions of their environment are excluded from this PLOS model.

In recent years, Google tools have been applied in pedestrian assessment studies (Bader et al., 2015; Griew et al., 2013) to reduce the 
audit cost and time. Some efforts have also been made to assess the feasibility of these tools (Aghaabbasi, Moeinaddini, Shah, AsadiShekari, \& Kermani, 2018; Bethlehem et al., 2014; Kelly, Wilson, Baker, Miller, \& Schootman, 2013; Phillips et al., 2017; Vanwolleghem, Van Dyck, Ducheyne, De Bourdeaudhuij, \& Cardon, 2014; Wu et al., 2014; Zhua et al., 2017). Most of these studies mention that applying virtual assessment for detailed attributes and facilities remains time-consuming and sometimes impossible.

Existing PLOS methods lack reliable measures and assessment tools for pedestrians with various abilities (Asadi-Shekari et al., 2013b). Existing models cannot be used to evaluate street conditions for various users. For instance, many of the previous PLOS models assumed that pedestrians did not have a disability (Asadi-Shekari et al., 2013a). In addition, although lots of existing PLOS models focus on a macro-scale view (e.g., Jaskiewicz, 1999; Muraleetharan, Adachi, Hagiwara, \& Kagaya, 2005; Petritsch et al., 2006), micro design factors are more important for identification of the quality of the walking environment (Southworth, 2005). Therefore, this study seeks to develop innovative PLOS models, which explain and evaluate inclusive streets for walking, focusing on universal micro-level design factors for a wide range of street users, in particular disabled people, while considering pedestrian perceptions of their environment.

\section{Method}

The majority of pedestrian facilities and the standards needed to ensure that sidewalks provide inclusive walking conditions, are identified by reviewing advanced guidelines, current literature and expert interviews. This reviewing process aimed to find new indicators and was stopped when all indicators became repeated. The final list of indicators identified in the reviewing process was presented at a meeting of experts, including architects, urban planners and transport planners, to ensure that all relevant indicators were present in the final list.

These indicators were then used to prepare a questionnaire for data collection, focusing on the importance of these indicators for inclusive pedestrian-friendly streets. The questionnaire has two main parts. The first part relates to personal information and socio-demographic status, and the second part includes the level of importance for each indicator. Respondents can rate the indicators and facilities from least important to extremely important using a 5-point rating system. A total of 599 respondents, who were living in the Setia Tropika district, were randomly selected. This district is a new residential area in Johor, Malaysia. Johor state is very close to Singapore and is located in southern Malaysia.

In the first step, principal axis factor (PAF) analysis with a varimax rotation is used, a common method for exploratory factor analysis (EFA), to find underlying patterns among items in the questionnaire. The Kaiser-Meyer-Olkin (KMO) is used to test sampling adequacy. The minimum acceptable value is 0.70 (Hair et al., 2014). Cronbach's alpha value also tests reliability based on inter-correlations and the minimum acceptable value is 0.70 (Hair et al., 2014). Results of the varimax rotation can show underlying patterns when loadings less than 0.40 are excluded.

In the second step, confirmatory factor analysis (CFA) is used to determine the relationships between observed variables and latent variables (underlying patterns that are achieved in the first step). To do this, a path diagram, which is common practice in structural equation models (SEM), is applied. This diagram includes rectangles or squares that represent observed variables; elliptics or ovals and circles that represent latent variables; and circles with a single-headed arrow that represents error terms. The acceptable level of association to extract significant factors is defined by squared factor loading values more than 0.40 and the maximum likelihood (ML) technique is used to estimate the parameters. Common CFA fitting tests are used to test the fitness of the model, such as the chi-square test (X2) and normed chi-square (X2/ df); goodness-of-fit index (GFI) and adjusted goodness-of-fit index
(AGFI); root mean square error of approximation (RMSEA) and comparative fit index (CFI).

In the third step, second order confirmatory factor analysis (SOCFA) is used to determine the relationships between latent variables (underlying patterns that are achieved in PAF analysis) and the main latent variable (inclusive streets for walking). The acceptable level of association and model fitting tests are similar to CFA. The results of SOCFA can be used to identify the weight of each latent variable and observed variable when explaining inclusive streets for walking. The resulting factor loading values can be used as weights to estimate street facilities and infrastructure levels of service for pedestrians. Mathematically, this pedestrian level of service (PLOS) can be defined as follows: (refer to Eq. (1)):

$\mathrm{PLOS}=\sum_{i=1}^{n} W_{l v_{i}} \times \operatorname{PLOS}_{l v i}$

where: $P L O S=$ pedestrian level of service, $\mathrm{W}=$ weight and $\operatorname{lv}_{i}=$ latent variables.

Each underlying pattern (latent variable) does not have the same effects on the proposed PLOS. Therefore, each one can have a specific coefficient (weight) based on its association with inclusive streets for walking. The importance and priority of each latent variable is illustrated by its coefficient or weight, and factor loading value is used to represent this weight. The same process can be used to define PLOS for each underlying pattern or latent variable (refer to Eq. (2)):

$\operatorname{PLOS}_{l v_{i}}=\sum_{j=1}^{n} W_{o v_{j}} \times S_{o v_{j}}$

where: PLOS $=$ pedestrian level of service, $\operatorname{lv}_{i}=$ latent variables, $\mathrm{W}=$ weight, $\mathrm{S}=$ score and $\mathrm{ov}_{j}=$ observed variables for related latent variable.

Each observed variable does not have the same effects on the proposed PLOS for the latent variables. Therefore, each one can have a specific coefficient or weight based on its association with inclusive streets for walking and factor loading value is used to represent this weight. $S$ is a score between 0 and 1 . This score can be achieved by comparing the existing condition with the standard condition mentioned in advanced guidelines and current literature. Therefore, this study also reviews standards for various facilities in different conditions. This reviewing process was also based on finding new standards and was stopped when all standards became repeated. For the standards that are different in various guidelines and studies, the most complete and pedestrian-friendly ones are selected. Standards from various guidelines are also combined to produce more complete and pedestrianfriendly standards. Appendix A indicates the standards collected for significant street factors, which are evaluated by the proposed PLOS model in this study.

Table 1

Rotated factor matrix that represents inclusive streets for walking.

\begin{tabular}{|c|c|c|c|}
\hline & \multicolumn{3}{|l|}{ Factor } \\
\hline & 1 & 2 & 3 \\
\hline 1 Curb ramp & 0.612 & & \\
\hline 2 Bollard & 0.552 & & \\
\hline 3 Driveway & 0.498 & & \\
\hline 4 Ramp & 0.468 & & \\
\hline 5 Tactile pavement & 0.466 & & \\
\hline 6 Width of the sidewalk & 0.451 & & \\
\hline 7 Surface material & 0.450 & & \\
\hline 8 Lighting & & 0.679 & \\
\hline 9 Landscape and tree & & 0.641 & \\
\hline 10 Sitting area & & 0.522 & \\
\hline 11 Toilet & & & 0.764 \\
\hline 12 Trash receptacles & & & 0.619 \\
\hline 13 Drinking Fountain & & & 0.492 \\
\hline 14 Elevator & & & 0.464 \\
\hline
\end{tabular}




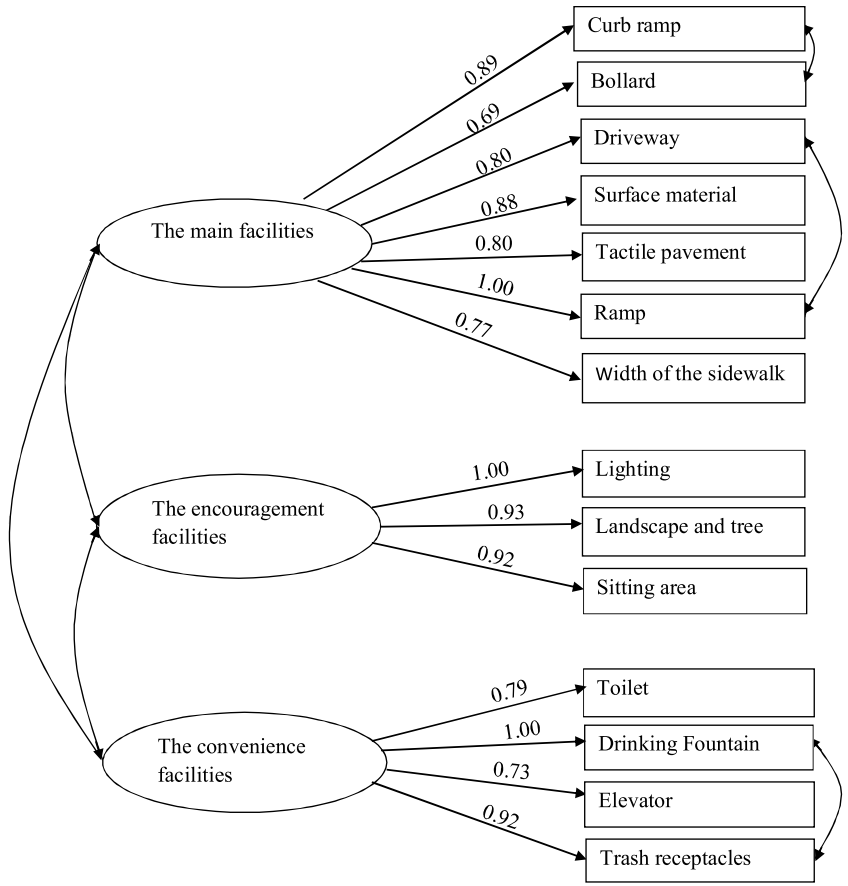

Fig. 1. Final CFA model that represents inclusive streets for walking model.

$S$ can be 0 for existing conditions that completely fail to fulfil the standards. This score can be 1 when conditions completely fulfil the standards. There are also some scores between 0 and 1 when the fitness between existing conditions and standards is semi-complete. This points system (comparison with standards) is used in various scoring methods and a similar scoring method for PLOS has been used by Asadi-Shekari et al. (2013a, 2014, 2015b). Appendix B shows the process of scoring and comparing existing conditions with standards for each $S$. The maximum score for each $S$ is 1 . Therefore, the PLOS percentage that is
Table 2

The model fitting indices.

\begin{tabular}{llll}
\hline Model indices & Default model & Saturated model & Independence model \\
\hline CMIN & 247.756 & 0 & 2462.454 \\
$d f$ & 71 & 0 & 91 \\
$p$ & 0.0001 & - & 0.0001 \\
CMIN $/ d f$ & 3.490 & - & 27.060 \\
GFI & 0.944 & 1.000 & 0.445 \\
AGFI & 0.918 & - & 0.360 \\
NFI & 0.899 & 1.000 & 0.000 \\
TLI & 0.904 & - & 0.000 \\
CFI & 0.925 & 1.000 & 0.000 \\
RMSEA & 0.064 & - & 0.209
\end{tabular}

CMIN $=$ Chi-square, $d f=$ degree of freedom, $p=$ p-value for chi-square test, $\mathrm{CMIN} / \mathrm{d} f=$ the Normed chi-square, GFI $=$ Goodness-of-Fit index, AGFI $=$ Adjusted Goodness-of-Fit Index, NFI $=$ Normed Fit Index, TLI $=$ TuckerLewis Index, CFI $=$ Comparative Fit Index, RMSE $=$ Root Mean Square Error of Approximation.

the percentage of existing PLOS of the ideal PLOS (all scores are equal to 1) for the proposed PLOS can be defined as follows: (refer to Eqs. (3) and (4)):

$\operatorname{PLOS} \%=\frac{\sum_{i=1}^{n} W_{l v_{i}} \times \operatorname{PLOS}_{l v_{i}} \%}{\sum_{i=1}^{n} W_{l v_{i}} \times 100} \times 100$

where: PLOS $\%=$ pedestrian level of service percentage, $l_{i}=$ latent variables, $\mathrm{W}=$ weight, PLOS $l v_{i} \%=$ pedestrian level of service percentage for latent variables.

$\operatorname{PLOS}_{l v_{i}} \%=\frac{P L O S_{l v_{i}}}{\sum_{j=1}^{n} W_{o v_{j}}} \times 100$

where: PLOS ${ }_{l v_{i}} \%=$ pedestrian level of service percentage for latent variables, $\mathrm{lv}_{i}=$ latent variables, $\mathrm{W}=$ weight, $\mathrm{ov}_{j}=$ observed variables for related latent variable.

Most level-of-service (LOS) studies use some rating system from 0 to

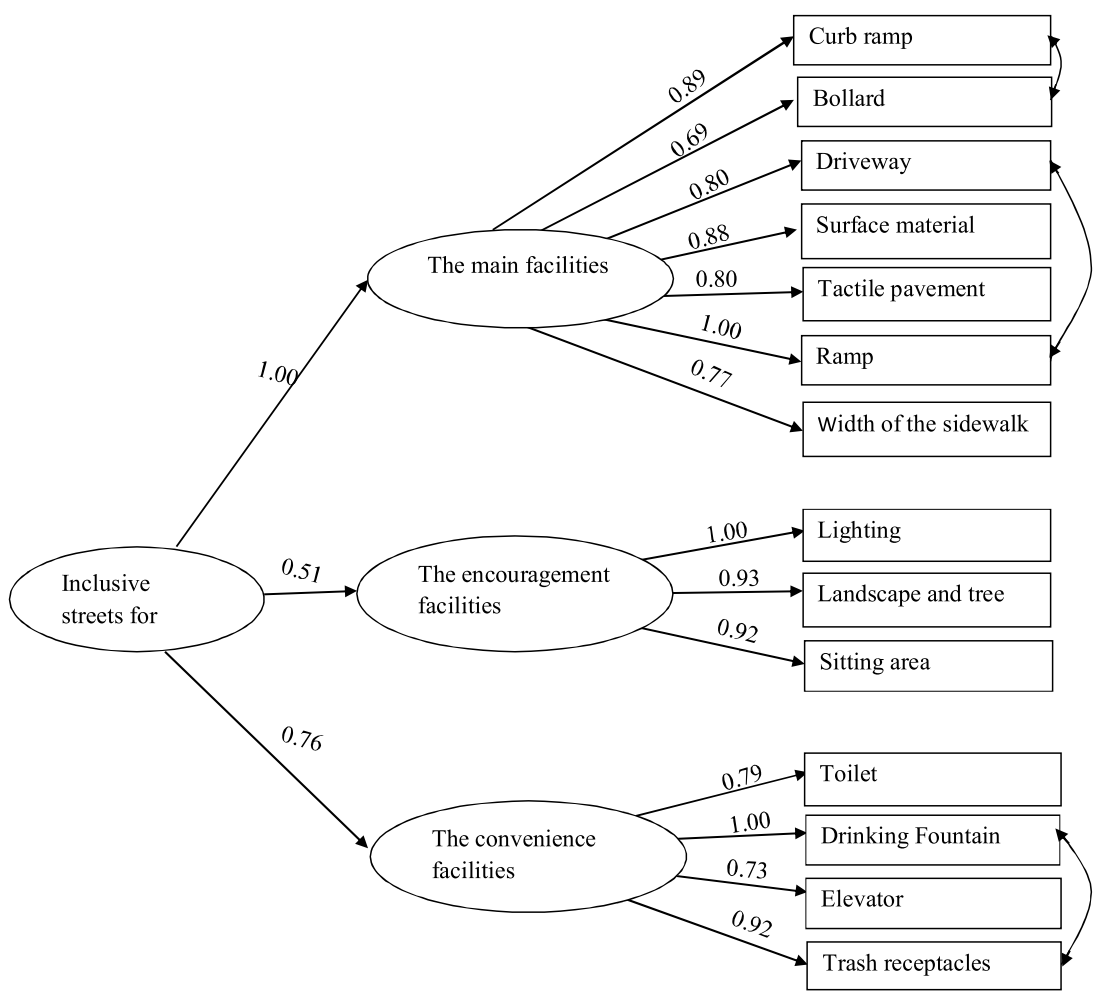

Fig. 2. Final SOCFA model that represents inclusive streets for walking model. 
100 or A to $\mathrm{F}$ to make the results more understandable (e.g., Fruin, 1971; Sarkar, 1993; Dixon, 1996; Landis et al., 2001; Sarkar, 2002; Jensen, 2007; Asadi-Shekari et al., 2013a, 2014). PLOS A (a PLOS percentage between 80 and 100) shows the highest fitness with the standards and indicates pedestrian-friendly conditions. PLOS B (a PLOS percentage between 60 and 79) shows that the existing conditions are acceptable, but some improvements are required. PLOS C (a PLOS percentage between 40 and 59) indicates that the street requires more improvements. PLOS D (a PLOS percentage between 20 and 39) means the street requires considerable improvements. PLOS E (a PLOS percentage between 1 and 19) shows an unpleasant level of service for pedestrians and PLOS F (PLOS percentage $=0$ ) indicates that there are no standard pedestrian facilities on the street.

\section{Results}

Different urban streets can be evaluated by this PLOS model since the indicators and standards are selected from advanced guidelines and current literature, regardless of the context effects. The universal microlevel design allows implementation of this method in various urban streets in different cities. However, the coefficients (weights) that are estimated by SEM can be used to localize the proposed PLOS.

The street used in this research to test the proposed PLOS is a collector street in the Setia Tropika area of Johor Bahru, Malaysia, which is a new residential area with more pedestrian facilities than similar areas in Johor Bahru. Pedestrian facilities evaluated in this area include the facilities on Main Street in Setia Tropika. The street segment evaluated is $1790 \mathrm{~m}$ long. This length can be used to represent the typical range of pedestrian facilities on this street.

Table 1 shows the results of a PAF analysis with a varimax rotation for the Likert scale questions in the questionnaire, while the KMO value (0.875) and Cronbach's alpha value (0.848) are at an acceptable level. Table 1 shows that seven items loaded onto the first factor. Since most of these items are related to the basic facilities needed for walking on inclusive streets, the first factor is labelled 'main facilities'. Three items loaded onto factor number two. Brighter levels of light can increase feelings of safety and encourage walking at night. Lighting in this study is related to the pedestrian lighting scale, which is added to the usual streetlighting to give brighter levels of light for pedestrians at night. This factor, in addition to other walking 'encouragement' factors (such as seating areas, the landscape and trees) can be categorized as encouragement facilities. Therefore, the second factor is labelled 'encouragement facilities'. Four items loaded onto the last factor. Since most of these items are related to the facilities needed for convenient walking, the last factor is labelled 'convenience facilities'.

CFA is used to determine the relationships between observed variables and underlying patterns (factors one, two and three) that are achieved from PAF analysis (see Table 1). Fig. 1 presents the final CFA model constructed for inclusive pedestrian-friendly streets. SOCFA is used to determine the relationships between latent variables (the underlying patterns that are factors one, two and three) and the main latent variable (inclusive streets for walking). Fig. 2 presents the final constructed SOCFA model, which explains inclusive streets for walking. Table 2 shows the goodness-of-fit tests for the proposed models. The results of SOCFA can be used to identify the weight of each latent variable and observed variable when explaining inclusive streets for walking. Table 3 shows that all the model estimates are statistically significant at a level of 0.001 .

The importance and priority of latent variables and observed variables can be illustrated by their weights, and factor loading values (see Fig. 2) are used to represent these weights. Based on the proposed equations, scores for the observed variables are needed to estimate related PLOSs in addition to the estimated weights. The length of the street selected for this research is $1722 \mathrm{~m}$ on one side, without considering intersections. A sidewalk is provided along this section of the street and on the opposite side. Setia Tropika has various widths of footpath pavement. The width of the footpath pavement is $1.18 \mathrm{~m}$ for $490 \mathrm{~m}$ of the street and $1.5 \mathrm{~m}$ for $1232 \mathrm{~m}$ of the street. These widths are the same on the opposite side so, in total, the footpath pavement is $1.18 \mathrm{~m}$ wide for $980 \mathrm{~m}$ of the street and $1.5 \mathrm{~m}$ wide for $2464 \mathrm{~m}$. Both of these widths are less than the minimum standard width, which is $1.8 \mathrm{~m}$. However, they have a standard footpath pavement. Appendix B shows the method of comparing existing conditions with the standards to achieve a suitable score for this variable. All scores for pedestrian facilities (observed variables) can be calculated by comparing existing conditions with the standards for each facility (see Appendixes A and B). Table 4 summarizes the scores, PLOS weights and PLOS percentage for the Main Street in Setia Tropika, based on Eqs. (1)-(4), and Appendixes A and B. The PLOS grade for this street is $\mathrm{C}$ according to the defined grades in this method, indicating that this street requires some improvements.

\section{Discussion and conclusions}

Suitable and enough infrastructures and facilities should be provided for pedestrian-friendly streets. Accordingly, a practical and suitable PLOS model is needed to evaluate pedestrian facilities and indicate improvements. Most previous PLOS methods have considered a limited range of pedestrian facilities. In addition, there are limited studies focusing on micro-level design factors, which have significant effects on the level of service. Moreover, the methodology of previous PLOS models is not easy to follow and cannot be connected to the

Table 3

The model estimates.

\begin{tabular}{|c|c|c|c|c|c|c|}
\hline & & & Estimate & S.E. & C.R. & $P$ \\
\hline The main facilities & $<-$ & Inclusive streets for walking & 1.000 & & & \\
\hline The encouragement facilities & $<-$ & Inclusive streets for walking & .510 & .062 & 8.200 & $* * *$ \\
\hline The convenience facilities & $<-$ & Inclusive streets for walking & .760 & .094 & 8.099 & $* k * *$ \\
\hline Curb ramp & $<-$ & The main facilities & .890 & .067 & 13.296 & $* * * *$ \\
\hline Bollard & $<-$ & The main facilities & .686 & .063 & 10.841 & $* * * *$ \\
\hline Driveway & $<-$ & The main facilities & .803 & .070 & 11.533 & **** \\
\hline Surface material & $<-$ & The main facilities & .881 & .061 & 14.388 & $* * * *$ \\
\hline Tactile pavement & $<-$ & The main facilities & .800 & .065 & 12.376 & $* * * *$ \\
\hline Ramp & $<-$ & The main facilities & 1.000 & & & \\
\hline Width of the sidewalk & $<-$ & The main facilities & .770 & .057 & 13.403 & $* w$ \\
\hline Lighting & $<-$ & The encouragement facilities & 1.000 & & & \\
\hline Landscape and tree & $<-$ & The encouragement facilities & .928 & .079 & 11.746 & $* * * *$ \\
\hline Sitting area & $<-$ & The encouragement facilities & .924 & .083 & 11.107 & $* * * *$ \\
\hline Toilet & $<-$ & The convenience facilities & .786 & .065 & 12.108 & $* k * *$ \\
\hline Drinking Fountain & $<-$ & The convenience facilities & 1.000 & & & \\
\hline Elevator & $<-$ & The convenience facilities & .726 & .072 & 10.143 & $* * *$ \\
\hline Trash receptacles & $<-$ & The convenience facilities & .916 & .074 & 12.379 & $* k *$ \\
\hline
\end{tabular}

$* * *$ The $\mathrm{p}$ value is less than 0.001 
design process. Therefore, this study proposes a new PLOS model to fulfil the needs of pedestrians by considering various facilities extracted from a wide range of developed guidelines, literature and interviews. The rating system used in the proposed PLOS model to evaluate pedestrian facilities at a micro level is easy to follow.

Various research emphasizes the lack of ability among existing studies to include the right combination of related factors for the facility evaluation process in PLOS studies. Maghelal and Capp (2011) focused on consideration of built environment attributes, which need to be combined with other effective factors for PLOS analysis. Singh and Jain (2011) argued that current PLOS methods are not inclusive for the entire walking environment. Kadali and Vedagiri (2016) emphasized the need to create a method that combines quantitative and qualitative factors to assess PLOS. The main contribution of the proposed PLOS model in this study is the right combination of all factors involved.

The model proposed in this study is applied to a collector street in the Setia Tropika area of Johor Bahru, Malaysia, and the same process can be applied to estimate the proposed PLOS for other street types or cities around the world. However, appropriate standard changes, and PAF, CFA and SOCFA recalculations for other cities and areas, should be considered. Therefore, the proposed PLOS can be utilized universally since the standards that are used in this model are extracted from universal standards. It can also be localized by applying PAF, CFA and SOCFA in the case study.

The limited number of advanced (and recent) PLOS models indicate the problems with pedestrian-friendly streets and suggest improvements in order to raise PLOS grades (e.g., Asadi-Shekari et al., 2013a, 2014). However, these models do not consider users' perceptions and just focus on guidelines and literature. The proposed PLOS model in this study can be used to improve existing conditions, while considering pedestrians' perceptions. These improvements can be determined by comparing existing conditions with standards. For instance, the score for landscape and trees (see Table 3 and Appendix B) can be increased from $0.62(D=15, C=((1790 \times 2)-179) \times 9 / 15=2040.6, N=$ $(1790 \times 2)-179=3401, \quad P_{1}=2040.6 / 3401=0.60, \quad F=2040.6-$ $0=2040.6, \quad P_{2}=2040.6 / 3401=0.60, \quad N I=2, \quad I=3, \quad P_{3}=2$ / $3=0.67$; so, $S=(0.60+0.60+0.67) / 3=0.62)$ to 1 if distances between trees are decreased from $15 \mathrm{~m}$ to $9 \mathrm{~m}$ and trees located at the stipulated standard distance (at two intersections) are removed. Scores for rubbish bins (see Table 3 and Appendix B) can also be increased from $0.25(C=500+400=900 \mathrm{~m}, N=1790 \times 2=3580 \mathrm{~m}, S=$ $900 / 3580=0.25$ ) to 1 if rubbish bins are provided along $2680 \mathrm{~m}$ of the street. All improvements can be found by the same process. These improvements can be prioritized, based on the weights of the facilities estimated by SOCFA (see Table 3 ).

Results show that the 'main facilities' have the highest association with inclusive pedestrian-friendly streets, followed by 'convenience facilities' and 'encouragement facilities' (see Fig. 2). Among the main facilities, a ramp has the highest association, followed by a curb ramp, sidewalk pavement, tactile pavement, driveway, width of sidewalk and bollard (see Fig. 2). Among convenience facilities, drinking fountains have the highest association, followed by rubbish bins, toilets and a lift (see Fig. 2). Among encouragement facilities, lighting has the highest association, followed by the landscape, trees and seating areas (see Fig. 2).

The proposed PLOS can also be used to identify the type of pedestrian facilities that need further improvements. The PLOS score for the main facilities in Setia Tropika is 2.876 . The maximum PLOS available for the main facilities is 5.83 (see Table 3). Therefore, the PLOS percentage for the main facilities on this street is 49 (see Table 3 ) and the associated PLOS grade is C. This grade is the same for convenience facilities, but the PLOS percentage for encouragement facilities is 28 , which is associated with PLOS grade D. This shows that important encouragement facilities, such as lighting and seating areas, are inadequate on this street, while the main facilities and convenience facilities also need some improvement. 
Although this study just focuses on pedestrians, the street conditions for other non-motorized street users, such as cyclists, could be evaluated in further studies using a similar process. The model presented here could be modified for use with other human settlements, such as rural areas and suburban areas, by considering the standard changes for street types, and PAF, CFA and SOCFA recalculation for the weights. Future studies could develop the PLOS model in the form of software promoting an easier calculation process. The model could also be used by urban designers for the design of new inclusive, pedestrian-friendly streets, in addition to improving existing streets.

\section{Acknowledgments}

The authors wish to thank all of those who have supported this research for their useful comments during its completion. In particular, we would like to acknowledge the Universiti Teknologi Malaysia Research Management Centre (RMC) and Centre for Innovative Planning and Development (CIPD). The funding for this project is made possible through the research grant obtained from the Ministry of Education, Malaysia.

\section{Appendix A. Standards of pedestrian facilities for collector streets}

Sources: Asadi-Shekari et al. (2013a, 2014 and 2015b), Clarke (2008); City of Calgary (2008); Sutherland and Morrish (2006); City of Whittlesea (2009); NARRABRR SHIRE COUNCIL (2001); City of Charles Sturt (2009); Heramb (2007); Vanderslice (1998); Ashland City Council (1999); Access Minneapolis (2008); CDOT (2007); Pima County (2005); Neighborhood Streets Project Stakeholders (2000); City of Aurora (2007); Burden (1999); Boodlal (2001); UTTIPEC (2009); NewYork City Department of Transportation (2009); RDM (2010) and City of Tacoma (2009)

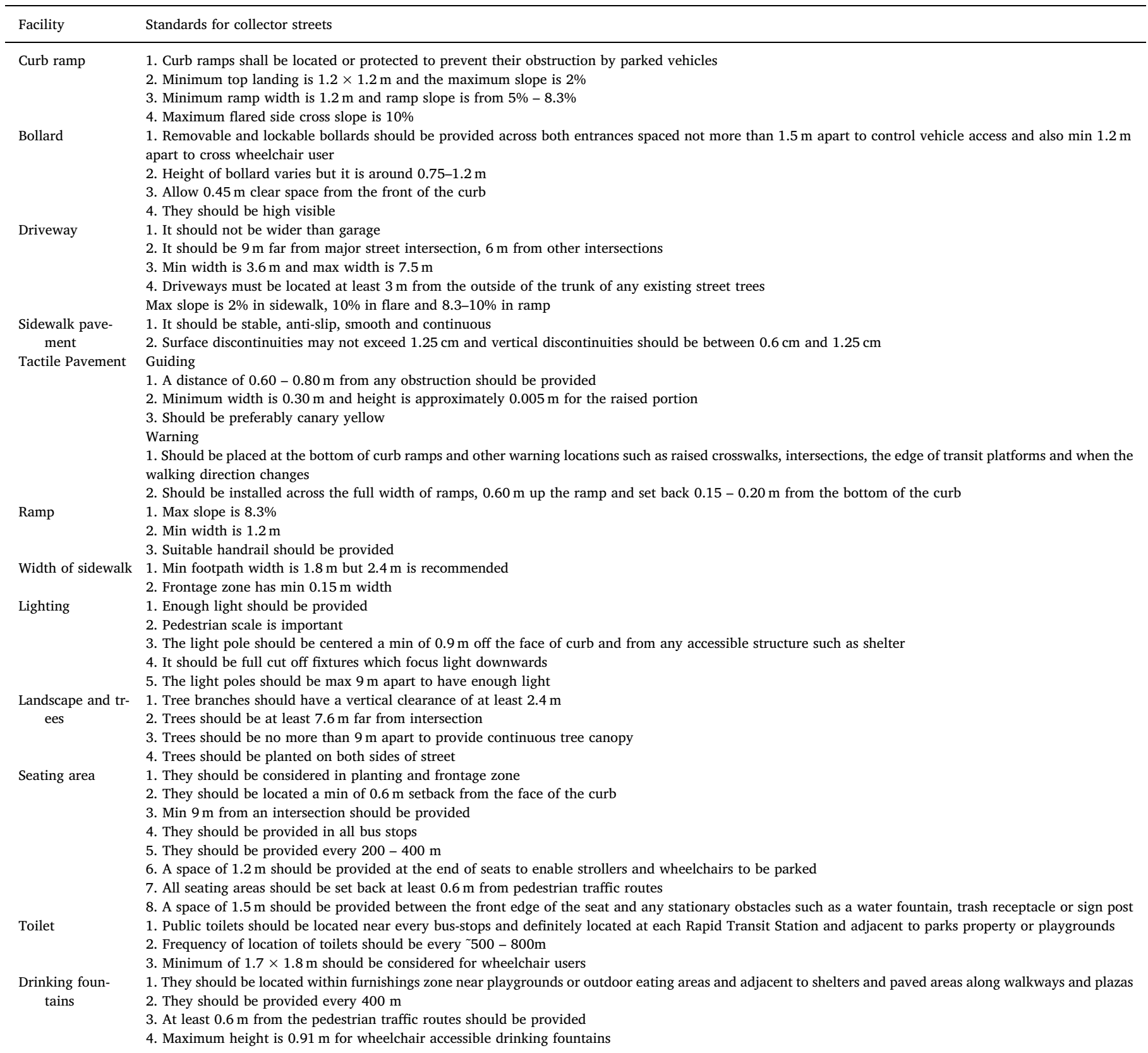


Elevator $\quad$ 1. Each sky bridge should have lifts, and all lifts should have Braille buttons and audio announcement systems

2. Elevator/lift should be provide on both the entrances and exits of the sky bridges and should have minimum internal dimensions of $1.4 \times 1.4 \mathrm{~m}$

3. Height of the call button is between 0.9 and $1 \mathrm{~m}$

4. Inside lift should have a handrail

Trash receptacles 1 . It should be centred in furnishing zone when zone is $0.9 \mathrm{~m}$ wide or greater

2. It should be $9 \mathrm{~m}$ far from intersection

3. Min $0.6 \mathrm{~m}$ from the face of curb should be provided

4. One receptacle should be located at each playground, and adjacent to benches

5. It should have min $1.2 \mathrm{~m}$ clearance from bus stop infrastructure

6. It should be provided every $200-400 \mathrm{~m}$ like bench

\section{Appendix B. $S$ calculation}

Sources: Asadi-Shekari et al. (2013a, 2014 and 2015b).

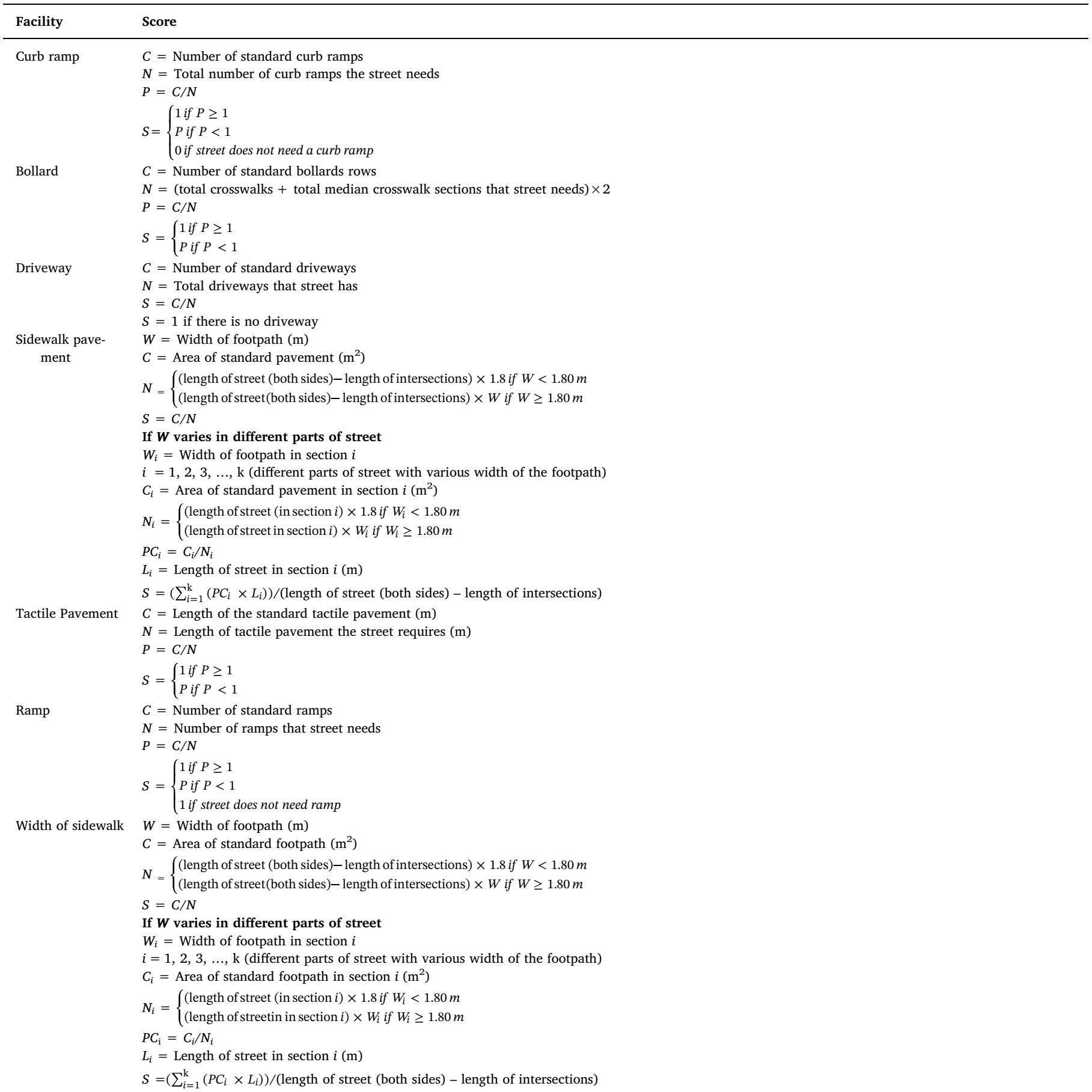


Lighting

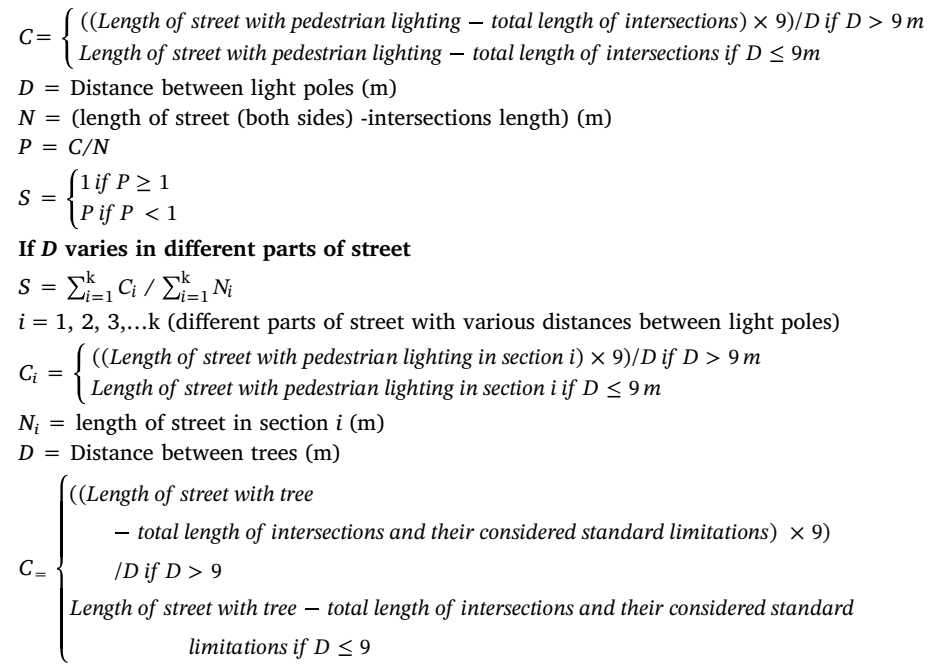

$N=$ Length of street (both sides)-total length of intersections and their considered standard limitations (m)

$P_{1}=C / N$

If $D$ varies in different parts of street

$C_{i}=\left\{\begin{array}{l}((\text { Length of street with tree in section } i \text { - considered standard limitations }) \times 9) / D \text { if } D>9 \\ \text { Length of street with tree in section } i-\text { considered standard limitations if } D \leq 9\end{array} \quad 1,2,3, \ldots, \mathrm{k}\right.$ (different parts of street with various distances between trees)

$N_{i}=$ Length of street (in section $i$ ) - considered standard limitations (m)

$P_{1}=\sum_{i=1}^{\mathrm{k}} C_{i} / \sum_{i=1}^{\mathrm{k}} N_{i}$

$F=C$ - length of street that does not have vertical clearance

$N=$ Length of street (both sides)-total length of intersections and their considered standard limitations (m)

$P_{2}=F / N$

If $\boldsymbol{D}$ varies in different parts of street

$F_{i}=C_{i}$ - length of street that does not have vertical clearance in section $i$

$N_{i}=$ Length of street (section $i$ )- considered standard limitations (m)

$P_{2}=\sum_{i=1}^{\mathrm{k}} F_{i} / \sum_{i=1}^{\mathrm{k}} N_{i} i=1,2,3, \ldots, \mathrm{k}$

$N I=$ Number of intersections with considered standard limitations for trees

$I=$ Number of total intersections

$P_{3}=N I / I$

$S=\left(P_{1}+P_{2}+P_{3}\right) / 3$

Seating area $\quad C=$ Length of street with standards seating area + their support length $(\mathrm{m})$

$N=$ Length of street (in both sides) (m)

$S=C / N$

Toilet $\quad C=$ Length of street with standards toilets + their support length $(\mathrm{m})$

$N=$ Length of street (m)

$S=C / N$

Drinking fountains $\quad C$ = Length of street with standards drinking fountains + their support length (m)

$N=$ Length of street (m)

$S=C / N$

Elevator $\quad C=$ Number of standard lifts

$N=$ Number of lifts that street needs

$S=C / N$

$S=0$ If street does not have lift

Trash receptacles $\quad C=$ Length of street with standards trash receptacle area + their support length $(\mathrm{m})$

$N=$ Length of street (both sides) (m)

$S=C / N$

\section{References}

Access Minneapolis (2008). Design guidelines for streets and sidewalks. Minneapolis, MN The Minneapolis Depatment Of Public Works.

Aghaabbasi, M., Moeinaddini, M., Shah, M. Z., \& Asadi-Shekari, Z. (2017). A new assessment model to evaluate the microscale sidewalk design factors at the neighbourhood level. Journal of Transport \& Health, 5, 97-112.

Aghaabbasi, M., Moeinaddini, M., Shah, M. Z., \& Asadi-Shekari, Z. (2018). Addressing issues in the use of Google tools for assessing pedestrian built environments. Journal of Transport Geography, 73, 185-198.

Aghaabbasi, M., Moeinaddini, M., Shah, M. Z., Asadi-Shekari, Z., \& Kermani, M. A. (2018). Evaluating the capability of walkability audit tools for assessing sidewalks. Sustainable Cities and Society, 37, 475-484.

Asadi-Shekari, Z., Moeinaddini, M., \& Zaly Shah, M. (2014). A pedestrian level of service method for evaluating and promoting walking facilities on campus streets. Land Use Policy, 38, 175-193.

Asadi-Shekari, Z., Moeinaddini, M., \& Zaly Shah, M. (2013a). Disabled pedestrian level of service method for evaluating and promoting inclusive walking facilities on urban streets. Journal of Transportation Engineering, 139, 181-192.

Asadi-Shekari, Z., Moeinaddini, M., \& Zaly Shah, M. (2015a). A bicycle safety index for evaluating urban street facilities. Traffic Injury Prevention, 16, 283-288.

Asadi-Shekari, Z., Moeinaddini, M., \& Zaly Shah, M. (2013b). Non-motorised level of service: Addressing challenges in pedestrian and bicycle level of service. Transpor Reviews, 33, 166-194.

Asadi-Shekari, Z., Moeinaddini, M. \& Zaly Shah, M. (2015b). Pedestrian safety index for evaluating street facilities in urban areas. Safety Science, 74, 1-14.

Ashland City Council (1999). Street standard handbook. Ashland, OR: Department of community development.

Bader, M. D., Mooney, S. J., Lee, Y. J., Sheehan, D., Neckerman, K. M., Rundle, A. G., et al. (2015). Development and deployment of the computer assisted neighborhood visual assessment system (CANVAS) to measure health-related neighborhood conditions. Health \& Place, 31(1), 163-172.

Bethlehem, J. R., Mackenbach, J. D., Ben-Rebah, M., Compernolle, S., Glonti, K., Bárdos, H., et al. (2014). The SPOTLIGHT virtual audit tool: A valid and reliable tool to assess obesogenic characteristics of the built environment. International Journal of Health Geographics, 13(1), 1-8.

Boodlal, L. (2001). Accessible sidewalks and street crossings. U.S. Department of Transportation.

Burden, D. (1999). Street Design Guidelines for Healthy Neighborhoods. TRB Circular E-C019: Urban Street Symposium.

CDOT (2007). Charlotte's urban street design guideline. Charlotte, NC: Charlotte Department 
of Transportation.

Christopoulou, P., \& Pitsiava-Latinopoulou, M. (2012). Development of a model for the estimation of pedestrian level of service in Greek urban areas. Procedia-Social and Behavioral Sciences, 48, 1691-1701.

City of Aurora (2007). Aurora urban street standards in transit oriented developments and urban centers. Aurora, CO.

City of Calgary (2008). Pedestrian policy and design reportCalgary, Alberta, Canada.

City of Charles Sturt (2009). Engineering \& open space development guidelines - road and path design guidelines. Charles Sturt, South Australia.

City of Tacoma (2009). Mobility master plan bicycle and pedestrian design guidelines, Tacoma mobility master plan 1. Tacoma, WA.

City of Whittlesea (2009). City of Whittlesea Development Guidelines. Municipal policy direction. Whittlesea, Australia.

Clarke, R. A. (2008). City of Ottawa road corridor planning \& design guidelines. Ottawa: DELCAN Corporation, The Planning Partnership.

Clifton, K. J., Livi Smith, A. D., \& Rodriguez, D. (2007). The development and testing of an audit for the pedestrian environment. Landscape and Urban Planning, 80(1), 95-110.

Cubukcu, E. (2013). Walking for sustainable living. Procedia - Social and Behavioral Sciences, 85, 33-42.

Cunningham, G. O., Michael, Y. L., Farquhar, S. A., \& Lapidus, J. (2005). Developing a reliable senior walking environmental assessment tool. American Journal of Preventive Medicine, 29(3), 215-217.

De Vries, S. I., Bakker, I., Van Mechelen, W., \& Hopman-Rock, M. (2007). Determinants of activity-friendly neighborhoods for children: Results from the SPACE study. American Journal of Health Promotion, 21(4s), 312-316.

Dixon, L. (1996). Bicycle and pedestrian level-of-service performance measures and standards for congestion management systems. Transportation Research Record, 1538, 1-9.

Elias, W., \& Shiftan, Y. (2012). The influence of individual's risk perception and attitudes on travel behavior. Transportation Research Part A, Policy and Practice, 46(8), $1241-1251$.

Ettema, D., Gärling, T., Eriksson, L., Friman, M., Olsson, L. E., \& Fujii, S. (2011). Satisfaction with travel and subjective well-being: Development and test of a measurement tool. Transportation Research Part F, Traffic Psychology and Behaviour, 14(3), $167-175$.

Ewing, R., Handy, S., Brownson, R. C., Clemente, O., \& Winston, E. (2006). Identifying and measuring urban design qualities related to walkability. Journal of Physical Activity \& Health, 3, S223.

Fruin, J. J. (1971). Pedestrian planning and design. New York: Metropolitan Associations of Urban Designers and Environmental Planners.

Griew, P., Hillsdon, M., Foster, C., Coombes, E., Jones, A., \& Wilkinson, P. (2013). Developing and testing a street audit tool using google street view to measure environmental supportiveness for physical activity. The International Journal of Behavioral Nutrition and Physical Activity, 10(1), 1-7.

Hair, J., Hult, G. T. M., Ringle, C. M., \& Sarstedt, M. (2014). A Primer on Partial Least Squares Structural Equation Modeling (PLS-SEM). SAGE Publications.

HCM (2000). Highway capacity manual. Transportation research board. Washington, D.C: National Research Council.

Heramb, C. (2007). Street and site plan design standards. Chicago: Chicago Department of Transportation.

Holbrow, G. (2013). Sidewalk accessibility, sidewalk justice conceptions of equity in cities' prioritization of pedestrian accessibility improvements. Doctoral dissertationTUFTS UNIVERSITY.

Jaskiewicz, F. (1999). Pedestrian level-of-service based upon trip quality. Urban Street Symposium (TRB).

Jensen, S. (2007). Pedestrian and bicycle level of service on road way segments. Transportation Research Record, 2031, 43-51.

Kadali, B. R., \& Vedagiri, P. (2015). Evaluation of pedestrian crosswalk level of service (LOS) in perspective of type of land-use. Transportation Research Part A, Policy and Practice, 73, 113-124.

Kadali, B. R., \& Vedagiri, P. (2016). Review of pedestrian level of service perspective in developing countries. Transportation Research Record: Journal of the Transportation Research Board, (2581), 37-47.

Kang, Y., \& Xiong, F. L. (2013). Mannering, Statistical analysis of pedestrian perceptions of sidewalk level of service in the presence of bicycles. Journal of Transportation Research Part A, 53, 10-21.

Kelly, C. M., Wilson, J. S., Baker, E. A., Miller, D. K., \& Schootman, M. (2013). Using google street view to audit the built environment: Inter-rater reliability results. Annals of Behavioral Medicine: A Publication of the Society of Behavioral Medicine, 45(Suppl. 1), S108-S112.

Khisty, C. J. (1994). Evaluation of pedestrian facilities. Beyond the level-of-service concept. Transportation Research Record, 1438, 45-50.

Kihl, M., Brennan, D., Gabhawala, N., List, J., \& Mittal, P. (2005). Livable communities: An evaluation guide. Retrieved 28 June, 2014, fromhttp://assets.aarp.org/rgcenter/il/ d18311_communities.pdf.

Landis, B., Vattikuti, V., Ottenberg, R., McLeod, D., \& Guttenplan, M. (2001). Modeling the roadside walking environment: A pedestrian level of service. Transportation Research Record, 1773, 82-88.

Larsen, K. (2014). Safety and school travel: How does the built environment relate to correlates of safety, mode of travel and physical activity levels to and from school. University of Toronto.

Lautso, K., \& Murole, P. (1974). A study of pedestrian traffic in Helsinki: Methods and results. Traffic Engineering and Control, 15, 446-449.

Litman, T. (2012). Evaluating non-motorized transportation benefits and costs guide to valuing walking and cycling improvements and encouragement programs. Victoria, British
Columbia: Victoria Transport Policy Institute1-78.

Maghelal, P. K., \& Capp, C. J. (2011). Walkability: A review of existing pedestrian indices. Journal of the Urban and Regional Information Systems Association, 23(2), 5-19.

McDonald, N. C. (2007). Active transportation to school: Trends among US schoolchildren, 1969-2001. American Journal of Preventive Medicine, 32(6), 509-516.

Mehta, V. (2008). Walkable streets: Pedestrian behavior, perceptions and attitudes. Journal of Urbanism, 1(3), 217-245.

Miller, J. S., Bigelow, J., \& Garber, N. J. (2000). Calibrating pedestrian level-of-service metrics with 3-D visualization. Transportation Research Record, 1705, 9-15.

Moeinaddini, M., Asadi-Shekari, Z., Ismail, C. R., \& Zaly Shah, M. (2013). A practical method for evaluating parking area level of service. Land Use Policy, 33, 1-10.

Moeinaddini, M., Asadi-Shekari, Z., \& Zaly Shah, M. (2014a). The relationship between urban street networks and the number of transport fatalities at the city level. Safety Science, 62, 114-120.

Moeinaddini, M., Asadi-Shekari, Z., \& Zaly Shah, M. (2015a). Analyzing the relationships between the number of deaths in road accidents and the work travel mode choice at the city level. Safety Science, 72, 249-254.

Moeinaddini, M., Asadi-Shekari, Z., \& Zaly Shah, M. (2014b). Analyzing the relationship between park-and-ride facilities and private motorized trips indicators. Arabian Journal for Science and Engineering, 39(5), 3481-3488.

Moeinaddini, M., Asadi-Shekari, Z., \& Zaly Shah, M. (2015b). An urban mobility index for evaluating and reducing private motorized trips. Measurement, 63, 30-40.

Muraleetharan, T., Adachi, T., Hagiwara, T., \& Kagaya, S. (2005). Method to determine pedestrian level-of-service for crosswalks at urban intersections. Journal of the Eastern Asia Society for Transportation Studies, 6(1), 127-136.

NARRABRR SHIRE COUNCIL (2001). New South Wales Development design specification geometric road design. New South Wales, Australia.

Neighborhood Streets Project Stakeholders (2000). Neighborhood street design guidelines, an Oregon guide for reducing street widths. Oregon: A Consensus Agreement by the Stakeholder Design Team.

NewYork City Department of Transportation (2009). Street design manual. New York Otak (1997). Pedestrian facilities guidebook: Incorporating pedestrians into Washington's transportation system. Washington: Washington State Department of Transportation.

Petritsch, T. A., Landis, B. W., McLeod, P. S., Huang, H. F., Challa, S., Skaggs, C. L., et al (2006). Pedestrian level-of-service model for urban arterial facilities with sidewalks. Transportation Research Record, 1982, 84-89.

Phillips, C. B., Engelberg, J. K., Geremia, C. M., Zhu, W., Kurka, J. M., Cain, K. L., et al (2017). Online versus in-person comparison of Microscale Audit of Pedestrian Streetscapes (MAPS) assessments: Reliability of alternate methods. International Journal of Health Geographics, 16(27), 1-13.

Pima County (2005). Subdivision and development street standards. Pima County, AZ.

Rahimiashtiani, Z., \& Ujang, N. (2013). Pedestrian satisfaction with aesthetic, attractiveness and pleasurability: Evaluating the walkability of ChaharaghAbbasi Street in Isfahan, Iran. ALAM CIPTA. International Journal of Sustainable Tropical Design Research and Practice, 6(2), 13-22.

RDM (2010). Mn/DOT road design manual. Minnesota: Minnesota Department of Transportation.

Rodriguez, D. A., Aytur, S., Forsyth, A., Oakes, J. M., \& Clifton, K. J. (2008). Relation of modifiable neighborhood attributes to walking. Preventive Medicine, 47(3), 260-264.

Saelens, B. E., Sallis, J. F., \& Frank, L. D. (2003). Environmental correlates of walking and cycling: Findings from the transportation, urban design, and planning literatures. Annals of Behavioral Medicine, 25(2), 80-91.

Sahani, R., \& Kumar, B. P. (2017). Pedestrian level of service criteria for urban off-street facilities in mid-sized cities. Transport, 32(2), 221-232.

Sarkar, S. (1993). Determination of service levels for pedestrians, with European example. Transportation Research Record, 1405, 35-42.

Sarkar, S. (2002). Qualitative evaluation of comfort needs in urban walkways in major activity centers. TRB Annual Meeting.

Singh, K., \& Jain, P. K. (2011). Methods of assessing pedestrian level of service. Journal of Engineering Research and Studies, 2(1), 116-124.

Southworth, M. (2005). Designing the walkable city. Journal of Urban Planning and Development, 131(4), 246-257.

Sutherland, A., \& Morrish, G. (2006). Street design guidelines. In A. Petersen (Ed.). Landcom Australia.

Tan, D., Wang, W., Lu, J., \& Bian, Y. (2007). Research on methods of assessing pedestrian level of service for sidewalk. Journal of Transportation Systems Engineering and Information Technology, 7(5), 74-79.

Tanaboriboon, Y., \& Guyano, J. A. (1989). Level of service standards for pedestrian facilities in Bangkok: A case study. ITE Journal, 59(11), 39-41.

UTTIPEC (2009). Pedestrian design guidelines. New Delhi: Delhi Development Authority.

Vanderslice, E. (1998). Portland pedestrian design guide. Portland, OR: Office of Transportation Engineering and Development.

Vanwolleghem, G., Van Dyck, D., Ducheyne, F., De Bourdeaudhuij, I., \& Cardon, G. (2014). Assessing the environmental characteristics of cycling routes to school: A study on the reliability and validity of a google street view-based audit. International Journal of Health Geographics, 13(1), 1-9.

Williams, J. E., Evans, M., Kirtland, K. A., Cavnar, M. M., Sharpe, P. A., Neet, M. J., et al. (2005). Development and use of a tool for assessing sidewalk maintenance as an environmental support of physical activity. Health Promotion Practice, 6(1), 81-88.

Wu, Y.-T., Nash, P., Barnes, L. E., Minett, T., Matthews, F. E., Jones, A., et al. (2014) Assessing environmental features related to mental health: A reliability study of visual streetscape images. BMC Public Health, 14(1), 1-10.

Zhua, W., Suna, Y., Kurkab, J., Geremiac, C., Engelbergc, J. K., Cainc, K., et al. (2017). Reliability between online raters with varying familiarities of a region: Microscale Audit of Pedestrian Streetscapes (MAPS). Landscape and Urban Planning, 167(1), $240-248$. 